\title{
Biçim Sıfatlarında Etkin Alan Kurulumları: Yuvarlak Sıfatı Örneği
}

\author{
Ayşe Eda Gündoğdu \\ ORCID: 0000-0002-9074-7903 \\ Necmettin Erbakan Üniversitesi Sosyal ve Beşeri Bilimler Fakültesi Dilbilimi \\ Bölümü, Konya \\ aedagundogdu@gmail.com
}

(Gönderilme tarihi 17 Mayls 2020; kabul edilme tarihi 26 Ağustos 2020)

ÖZET: Anlam üretim sürecinde bireyin algısını ve bilisssel düzlemini en önemli değişken olarak ele alan bilişsel anlambilim çalışmaları özellikle son on yılda büyük bir ivme kazanmıștır. Psikoloji alanındaki kuramlardan da yararlanarak anlamın algı ve kavramlaştırmaya ilişkin bir üretim olduğunu savunan söz konusu disiplin çerçevesinde ortaya konan terimlerden biri de etkin alanlardır. Etkin alan kurulumları büyük oranda sıfatlar ve eylemler üzerinde gözlemlenmekle beraber, sıfatlarda etkin alanlar sıfat ve gönderimde bulunduğu ada ilișkin bilișsel eșleșmelerin hangi koșullarda ve ne șekilde çeşitlenebileceğini ortaya koymaya yardımcı olan bilişsel bir yapılanma olarak ele alınabilir. Bu çalışmada Türkçe biçim sıfatlarında etkin alan kurulumundaki dinamikleri yuvarlak sıfatı üzerinden ortaya koymak amaçlanmaktadır. Bu perspektifle araştırma konusu sıfatın Türkçe Ulusal Derlemi v3 (TUD v3) aracılığıyla bağımlı dizin görünümlerinden yararlanılmış ve söz konusu bağımlı dizinlerdeki kurulumlar içerik analizi yöntemiyle çözümlenmiştir.

Anahtar Sözcükler: Biçim sıfatı, yuvarlak, etkin alan, bilişsel anlambilim, derlem.

\section{Active Zone Constructions in Shape Adjectives: An Example of the} Adjective Yuvarlak

ABSTRACT: Cognitive semantics, which has gained acceleration in the last ten years, is a point of view that sees individual's perception and cognitive level as variables in meaning production process. Utilizing theories in psychology, one of the most important concepts put forward in the aforesaid discipline is active zones, which argues that meaning is a production related to conceptualization and perception. Active zone constructions in adjectives can be discussed as a cognitive structure that helps to display under what conditions and how the cognitive mappings of the adjective and the described noun can vary. In this 
study, it is aimed to reveal the dynamics in active zone constructions in Turkish shape adjectives in terms of the adjective yuvarlak. Within this perspective, cooccurrence appearances of the research topic adjective are obtained through Turkish National Corpus v3 and active zone constructions are analysed with content analysis method.

Keywords: Shape adjective, yuvarlak, active zone, cognitive semantics, corpus.

\section{Giriş}

Bilişsel anlambilim çalışmaları deneyim, kavramsal sistem ve dil aracılığıyla kodlanan anlamsal yapı arasındaki ilişkilere odaklanmaktadır. Bu açıdan bilişsel anlambilimin temel araştırma alanı kavramsal yap1 (bilgi gösterimi) ve kavramlaştırmanın (anlam üretimi) nasıl gerçekleştirildiği üzerinedir (Evans, 2007; 2012). Anlam üretimindeki soyut bilişsel alanları daha izlenebilir hale getiren dilsel veriler bu kapsamda en önemli araç haline gelmekte, dil aracılığıla bilişsel ve kültürel şemalar araştırma konusu yapılabilmektedir. Bilişsel anlambilim alanı bu kavramlaştırmaları kendi içerisinde farklı terminolojik bakış açılarıyla ele almaktadır. Söz konusu alanda kullanılan terminolojinin bir kısmını da etkin alan (active zone) kurulumları oluşturmaktadır. Langacker tarafindan alanyazına kazandırılan bir terim olan etkin alan kurulumlarına ilişkin çalışmalar, iki anlamsal içerik arasındaki eşleşmenin ne düzeyde ve hangi koşullarda gerçekleştiğini ortaya koymayı amaçlar. Langacker (1999) dilde iki anlamsal birim yan yana geldiğinde eşleşmenin ender olarak iki birimin de tamamını kapsadığını belirtmekte ve örnek olarak tümce (a) ve (b)'yi vermektedir:

(a) The spacecraft is now approaching Venus.

Uzay gemisi şimdi Venüs'e yaklaşıyor.

(b) Your dog bit my cat.

Köpeğin kedimi isırdl.

Tümce (a) incelendiğinde uzay gemisi ve Venüs'ün birbiri ile temasının bütünsel ve kapsayıcı olduğu görülmektedir. Diğer bir deyişle uzay gemisi, Venüs'ün fiziksel anlamda tamamına yaklaşmaktadır. Buna karşılık tümce (b) aracılığıyla kurgulanan sahnede köpeğin fiziksel anlamda kedinin tamamını 1sırması söz konusu değildir. Bu açıdan bütünüyle gerçekleşen ve kapsayıcı bir eşleşmeden söz etmek de mümkün değildir. Söz konusu etkin alan eşleşmeleri ya örnek tümcelerde olduğu gibi eylem/tamlayıcı etkileşimlerinde ya da sıfat/ad etkileşimlerinde doğrudan gözlemlenebilmektedir. Sifatlar açısından etkin alan kurulumu bağlamında Cruse (2000) red ve blue örneklerini vermekte ve bir sıfatın farklı adları tercih etmesi durumunda farklı etkin alan kurulumlarının gözlemlenebileceğini belirtmektedir: Örneğin "a red hat" öbeğinde kırmızı 
sıfatının bütün bir nesneyle eşleşmesi sağlanabilirken söz konusu sıfat "a red book" örneğinde yalnızca kitabın dış kapağıyla etkileşime girebilmektedir. Öte yandan, "a red pencil" örneği daha ilginç bir kurulumla karşımıza çıkmaktadır: Kırmızı sıfatı hem kalemin dış rengini hem de yazdığı rengi temsil etme potansiyeline sahiptir. Etkin alan kurulumu bağlamında "red eyes" ve "blue eye" örnekleri ele alındığında ise karşımıza daha karmaşık bir seçim ekseni çıkmaktadır: Kırmızı, ilk öbekte gözün beyaz kısmını etkin hale getirirken ikinci örnekte mavi, iris tabakasını etkin hale getirmektedir. Bu kapsamda, dillerde eylem/tamlayıcı ya da sıfat/ad etkileşimlerinde bütünsel-kapsayıcı bir eğilimden çok parçasal etkin alan kurulumlarının yaygın olduğu söylenebilir. Diğer bir deyişle, dil kullanıcıları farkında olmadan farklı etkin alan kurulumlarından yararlanmakta ve karşılaştığı anlamsal bir içeriği de bu kurulumlar doğrultusunda algılamaktadır.

Etkin alan kurulumlarının araştırma konusu yapılmasında psikoloji alanındaki Gestalt kuramı kapsamında ele alınan figür-zemin ilişkisinin payı büyüktür. Bilişsel anlambilim söz konusu ilişkiyi farklı terminolojiyle ele alsa da temelde dilsel üretimlerde de aynı kavramsal şema işlemektedir. Langacker (2004) bu bağlamda dilde figür-zemin ilişkisini araştırma konusu yaparken trajector (TR) ve landmark (LM) terimlerini tercih etmektedir. Bu çalışmada trajector "imleyen", landmark ise "sınır" terimleriyle karşılanmıştır. İmleyen (I) bilişsel bir şemada öncelenen/ön planda olan katılımcı iken sınır (S) daha az öne çıkan ve arka planda olan katılımcı olarak değerlendirilebilir. Bu bilgiler ışığında tümce (a) ve (b)'ye geri döndüğümüzde uzay gemisi İ, Venüs S olarak değerlendirilmekte ve İ-S kurulumunda tam eşleşme sağlanmaktadır. Köpek ve kedi içerikleri incelendiğinde ise köpek İ ve kedi S olarak değerlendirilmekte ve İ-S kurulumunda tam eşleşme sağlanamamaktadır. Langacker (2004: 5) tam eşleşmenin sağlanabildiği ve sağlanamadığı farklı İ-S profillemesi örnekleri vermektedir. Söz konusu örneklerin Türkçeye uyarlanmış biçimi Tablo 1'de yer almaktadır.

Tablo 1. Farklı I-S profilleme örnekleri (Langacker, 2004: 5)

(a) firındaki kek, zarftaki mektup, havadaki balon, yatak odasındaki şifonyer, midemdeki yiyecek

(b) sudaki kuğu, elindeki balta, hedefteki ok, kındaki kılıç, şişedeki mantar

(c) fincandaki su, akvaryumdaki balık, ekicideki kir, kese kağıdındaki yiyecekler, kalıptaki buz küpleri

(d) küvetteki adam, bardaktaki pipet, vazodaki çiçekler, kum kabındaki kedi, teknedeki kürekçi 
Şekil 1. Farkl İ-S profilleme sahneleri (Langacker, 2004: 5)

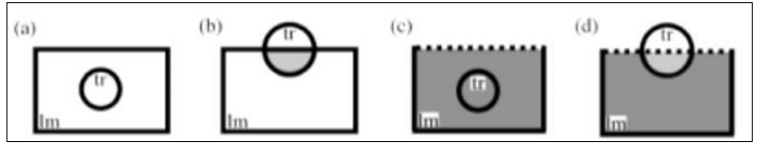

Tablo 1 ve Şekil 1 kapsamında, Langacker'ın belirttiği profilleme örnekleri incelendiğinde içerme/içerisinde bulunma senaryolarının birbirinden farklı biçimlerle kurgulandığı görülmektedir. Bu kapsamda firındaki kek, sudaki kuğu, fincandaki su ve küvetteki adam senaryoları ayn kodlayıc1yla (in ilgeciyle) dilsel düzleme çıksa da sınırın farklı alanlarıyla etkinleşerek kurulum sağlamaktadır. $\mathrm{Bu}$ bulgulara paralel olarak Gündoğdu (2019) Türkçede [sıfat+ad] ve [sıfat+bir+ad] kurulumlarını kırmızı sıfatı aracılığıyla ele almış ve kurulumların birbirinden farklı $\mathrm{I} / \mathrm{S}$ profillemelerine sahip olduğunu ortaya koymuştur. Türkçede [sıfat+ad] ve [sıfat+bir+ad] örüntülerinde her zaman tam eşleşme sağlanamamakta ve tam eşleşmenin sağlanamadığ 1 koşullarda farklı senaryolar üretilebilmektedir:

(a) Imleyen ve sinırın tamamen eşleştiği etkin alanlar: Ortadaki sehpada dün geceden kalmış bir şişe kırmızı şarap ve boş bir kadeh vardı. [WKA16B3A-0550-1532]

(b) Imleyenin sinırın öngörülebilir bir parçasıyla eşleştiği etkin alanlar: Dokunulabilir, tutulabilir ölçüde somut olan tek şey, kırmızı bir gül... [W-CA16B1A-2634-114]

(c) İmleyenin sinırın öngörülemez bir parçasıyla eşleştiği etkin alanlar: Kırmızı yanakları solmuş, eski güzelliğinden eser kalmamıştı. [WUA16B2A-1206-806]

(d) Imleyen ve sınıra ilişkin bulanık alanlar: Kırmızı kalemle kareli kâğıda yazılmış mektubu açıp okuyorum: Her satıra sinmiş korku, umarsızlık, ölüm halay çekiyordu. [W-IA16B3A-0871-1136]

Tümceler incelendiğinde İ/S eşleşmelerinin dört farklı düzlemde gerçekleştiği gözlemlenmektedir. Kırmızı şarap kurulumunda İ ve $\mathrm{S}$ tamamen eşleşirken kırmızı gül kurulumunda dil kullanıcısı tarafindan tahmin edilebilen bölgesel bir eşleşme sağlanmakta, kırmızı yanak kurulumunda ise bölgesel eşleşme dil kullanıcısı tarafından doğrudan tahmin edilememektedir. Öte yandan kirmızı kalem kurulumunda ise "kırmızı renkte olan kalem" ve "kırmızı yazan kalem" olmak üzere birbirinden farklı iki eşleşme senaryosundan bahsetmek mümkündür.

$\mathrm{Bu}$ çalışmanın temel amacı nesnelere fiziksel bir uzanım kazandıran biçim sıfatlarında adı etkinleştirmenin ardında yatan dinamikleri bilişsel anlambilim çerçevesinde ortaya koymaktır. Bu kapsamda yuvarlak sıfatı etkin alan kurulumları açısından derlem temelli bir perspektifle incelenmiştir. 


\section{Yöntem}

$\mathrm{Bu}$ araştırmada betimsel tarama yöntemi kullanılmıştır. Betimsel çalışmalar bilimin betimleme amacina hizmet etmekle birlikte, aynı zamanda kendinden sonraki çalışmalar için denence üretmeye yönelik öngörü sağlamaktadır (Erkuş, 2009). Araştırmada veriler içerik analizinin alt yöntemlerinden biri olan tematik analiz yöntemi ile çözümlenmiştir. İçerik analizi sözel, yazılı ve diğer materyallerin içerdiği mesajı, anlam ve/veya dilbilgisi açısından nesnel ve sistematik olarak sınıflandırma, sayılara dönüştürme ve çıkarımda bulunma yoluyla sosyal gerçeği araştıran bilimsel bir yaklaşımdır (Tavşancıl ve Aslan, 2001). Tematik analiz ise içerik analizi kapsamında, elde edilen veriler içerisinde tema ve örüntüler aramak amacıyla yapılan kodlamalara dayalı bir analiz yöntemidir (Glesne, 2013). Bu çalışmada yuvarlak sıfatının bağımlı dizin görünümleri TUD v3 aracılığıyla ortaya konmuş ve bu örüntülerdeki etkin alan kurulumları değerlendirilmiştir.

\subsection{Veri Seti}

$\mathrm{Bu}$ araştırmanın veri setini TUD v3 veritabanında yer alan metinler oluşturmaktadır. TUD v3 günümüz Türkçesinin dengeli, büyük ölçekli (50 milyon sözcük) ve genel amaçlı bir derlemi olacak biçimde tasarlanmıştır. TUD v3 50 milyon sözcükten oluşan, 24 yıllık bir dönemi (1990-2013) kapsayan, günümüz Türkçesinin çok sayıda farklı alan ve türlerden yazılı ve sözlü örneklerini içeren, geniş kapsamlı, dengeli ve temsil yeterliliğine sahip, genel amaçlı bir referans derlemdir. Kullanıcılar çok çeşitli kısıtlama ölçütleri ile (medya, metin örneklemi, konu alanı, türev metin biçimi, yazar cinsiyeti, hedef okur ve metin türü vb.) sorgularını gerçekleştirebilirler. Ayrıca TUD v3 sürümünde kullanıcılar sözcük türüne ve eklere göre de sorgu yapabilmekte; çoksözcüklü birimleri arayabilmektedir. Ayrıca sorgularını düzenli ifadeler olarak da gönderebilmektedir (https://v3.tnc.org.tr).

\subsection{Sinırlılıklar}

- Araştırmada TUD v3'te Yazılı Metin Sorgusu seçeneği kullanılmış ve standart arama yapılmıştır.

- Sifatın tümcede niteleyici konumundaki görünümleri kontrol edilmiştir. Sıfatın yüklemcil konumdaki etkinleştirme görünümlerinde etkinleştirilen adın her zaman belirgin olmaması nedeniyle, yüklemcil görünümlerin devam çalışması niteliğinde farklı bir çalışmada kendine özgü dinamikleriyle ele alınması planlanmaktadır.

- N-gram aralığ $[\mathrm{n}+1 / \mathrm{n}+2]$ ile sinırlı olup [yuvarlak+bir] dizilimleri araştırmaya dahil edilmemiştir. 


\subsection{Veri Toplama ve Çözümleme Süreci}

TUD v3 sorgu sonuçları kapsamında yuvarlak sıfatının bağlam içi anahtar sözcük görünümünden yararlanılmıştır. Şekil 2'de kullanılan arayüze ilişkin küçük bir kesit yer almaktadır.

Şekil 2. Yuvarlak sıfatı bağlam içi anahtar sözcük görünümü arayüzü

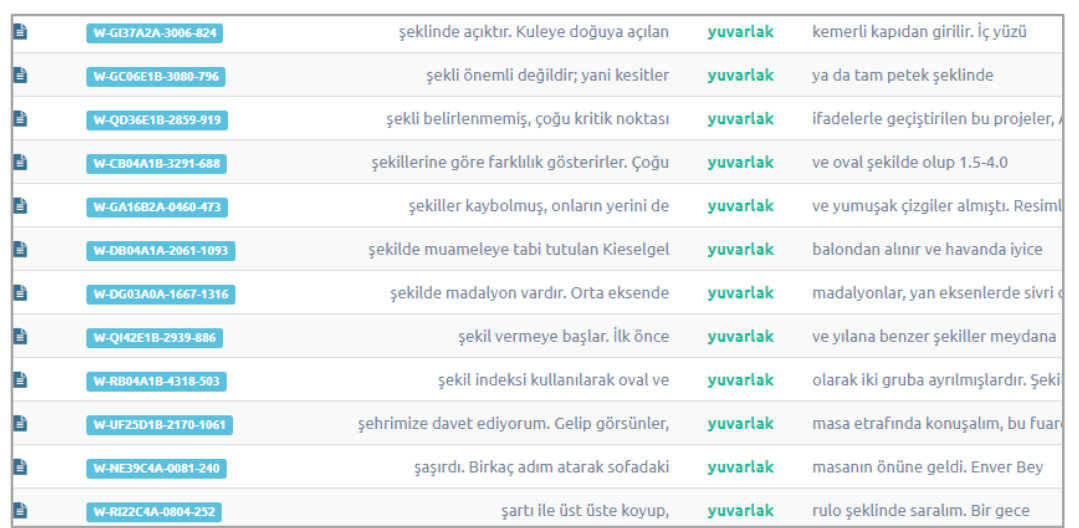

Bağlam içi anahtar sözcük görünümleri ortaya konduktan sonra sıfatın niteleyici konumundaki düzanlamsal kullanımları belirlenniş ve oluşturulan veri seti araştırmacı tarafından işlenip sınıflandırılmıştır.

\section{Bulgular ve Yorum}

\subsection{Giriş Gözlemleri}

Sıfatın TUD v3 kapsamındaki bağımlı dizin görünümleri 701 farklı metinde, 1587 sıklıkta karşımıza çıkmaktadır. Giriş gözlemlerinin ilk aşamasında yuvarlak sıfatının eşdizimlilik görünümleri betimlenmiştir (bkz. Tablo 2). 
Tablo 2. Yuvarlak sıfatının eşdizimlilik görünümleri ${ }^{12}$

\begin{tabular}{|c|c|c|c|c|c|}
\hline E. Sözcük & f & E. Sözcük & $\mathbf{f}$ & E. Sözcük & f \\
\hline masa & 140 & agrega & 7 & yaka & 4 \\
\hline kemer & 60 & çubuk & 7 & ağaç & 3 \\
\hline şekil & 44 & omuz & 7 & bina & 3 \\
\hline yüz & 37 & açıklık & 6 & boşluk & 3 \\
\hline kadran & 25 & cisim & 6 & çene & 3 \\
\hline biçim & 20 & kese & 6 & demir & 3 \\
\hline leke & 19 & köfte & 6 & domates & 3 \\
\hline balon & 18 & kurt & 6 & göğüs & 3 \\
\hline gövde & 17 & tahta & 6 & hamur & 3 \\
\hline hat & 17 & ağı1z & 5 & iz & 3 \\
\hline gözlük & 16 & alan & 5 & kağgtt & 3 \\
\hline kafa & 15 & $\operatorname{dip}$ & 5 & kalkan & 3 \\
\hline delik & 13 & form & 5 & kap & 3 \\
\hline taş & 13 & tepe & 5 & kapak & 3 \\
\hline tohum & 13 & apsis & 4 & kemik & 3 \\
\hline dilim & 12 & baş & 4 & kenar & 3 \\
\hline göz & 12 & cam & 4 & küre & 3 \\
\hline pencere & 12 & çıkıntı & 4 & meme & 3 \\
\hline çerçeve & 11 & daire & 4 & mühür & 3 \\
\hline niş & 11 & 1 1̧̧1k & 4 & odun & 3 \\
\hline tepsi & 11 & kalıp & 4 & oyuk & 3 \\
\hline ayna & 10 & kap1 & 4 & sehpa & 3 \\
\hline çizgi & 10 & kule & 4 & somun & 3 \\
\hline ekmek & 10 & kutu & 4 & surat & 3 \\
\hline kalça & 10 & madalyon & 4 & tane & 3 \\
\hline şey & 10 & nesne & 4 & yap1 & 3 \\
\hline uç & 10 & saat & 4 & yaprak & 3 \\
\hline top & 9 & solucan & 4 & yiv & 3 \\
\hline burun & 8 & & & & \\
\hline
\end{tabular}

\footnotetext{
${ }^{1}$ Bağımlı dizinlerdeki eşdizimliliklerden $\mathrm{f}>3$ ölçütünü karşılayanlar değerlendirilmeye alınmıștır.

${ }^{2}$ Tabloda sıfatın düzanlamsal görünümlerine ilişkin eşdizimlilikler yer almaktadır.
} 
Tablo 2 incelendiğinde doğrudan fiziksel nitelik kodlayan bir sıfat olması nedeniyle yuvarlak sifatının somut uzanımlara sahip adları tercih etme eğiliminde olduğu söylenebilir. Sıfatın ayrıca şekil, biçim hat, form gibi eşdizimsel ögelerle yaygın olarak kullanılması da fiziksel uzanıma sahip olmasıyla ilişkilendirilebilir. Tabloda masa, kemer ${ }^{3}$, şekil, yüz eşdizimsel ögelerinin yuvarlak sıfatıyla kullanımlarının diğer ögelere göre daha yaygın olduğu görülmektedir. Giriş niteliğinde bir gözlemle, yuvarlak sıfatının her zaman söz konusu ögelerin tamamını etkinleştiremediği söylenebilir: "yuvarlak masa" ve "yuvarlak kemer" öbeklerinde adın belirli bir bölümünün ya da noktasının etkinleştirildiği; "yuvarlak şekil" öbeğinde bağlam temelli olarak farklı etkinleşmelerin sağlanabileceği gözlemlenmektedir. "Yuvarlak yüz" öbeğinde ise $\dot{I} / S$ eşleşmesini net olarak senaryolaştırmak mümkün değildir. Ayrıca sıfatın agrega, niş, apsis, yiv gibi bilimsel ya da teknik alanlara ilişkin sözcüklerle kullanımı da elde edilen diğer bir ön bulgudur.

Yuvarlak sıfatı etkin alan kurulumu açısından incelenmeden önce sıfatın anlamsal sınırlarını çizmek amacıyla Türkçe sözlük sıfat görünümleri kontrol edilmiş ve Türk Dil Kurumu Türkçe Sözlük (2011) kapsamında iki farklı sıfat tanımıyla karşılaşılmıştır:

1. slfat Top veya küre biçiminde olan, müdevver: Yuvarlak bir yüz. Yuvarlak bir masa.

2. sıfat, mecaz Kesin ve açık olmayan (söz, laf vb.).

Çalışma doğrudan biçime ilişkin gönderimlerle sınırlı olduğu için bağımlı dizin görünümleri Tanım-1 kapsamında değerlendirilmiş ve değişmeceli anlam düzeyinde olan Tanım-2 kapsam dışı bırakılmıştır. Sözlükte yer alan "Top veya küre biçiminde olan, müdevver." tanımını tanık tümcelerle eşleştirildiğinde küresel, dairesel ve çembersel olmak üzere üç farklı uzanıma rastlanmıştır:

(a) İstanbul'da nelere inanılmadı ki (ve ola ki halen inanılıyor)? Dünyayı düşünelim, ilkin üzerinde yaşadığımız bu yuvarlak gezegeni... [WFI37C0A-1705-1445]

(b) Yuvarlak camlı gözlüklerini çıkartan Bahar, ellerini saçlarının arasında gezdirerek konuşmaya başlad1. [W-RA16B3A-0649-165]

(c) Büyüteç kullanırken çıkarması gerektiğinden ince, yuvarlak, metal çerçeveli gözlüğünü diğer elinde tutuyor. [W-RA16B2A-0629-490]

Tümce (a) incelendiğinde Tanım-1 kapsamında "top veya küre biçiminde olma" koşulu sağlanabilmekle birlikte tümce (b)'nin böyle bir koşulu karşılayamadığı, senaryonun dairesel bir algıyla belirli bir çember ve içerisindeki düzlem

\footnotetext{
${ }^{3}$ Kemer düğüm sözcüğü tanık tümcelerde "İki sütun veya ayağı birbirine üstten yarım çember.” (TDK, 2011) içeriğiyle kullanılmaktadır.
} 
gönderimiyle kurulduğu gözlemlenmektedir. Öte yandan tümce (c) incelendiğinde küresellik ve daireselliğin dışında, yalnızca çizgisel bir uzanımla karşılaşılmaktadır. Bu açıdan "yuvarlak gezegen”, "yuvarlak cam” ve "yuvarlak çerçeve" öbekleri, uzanımları biçimlendirme açısından birbirinden farklılaşmaktadır. Sonuç olarak yuvarlak sıfatının, eşdizimsel adın anlamsal içeriğine bağlı olarak küresel, dairesel ya da çembersel etkinleştirme eğiliminde olduğu söylenebilir. Çalışmada "küresellik/dairesellik/çembersellik uzanımları" etkin alan kurulumunda ilk değişken olarak belirlenmiştir.

Tanık tümceler incelendiğinde diğer bir değişkenin yuvarlaklık öntürü olduğu gözlemlenmektedir. Diğer bir deyişle, kurulumların bir kısmı kusursuz bir yuvarlak kurgusuyla kavramlaştırılırken bir kısmında yuvarlaklık kurulumu için "biçimsel açıdan yuvarlağa benzeme" koşulu yeterli olmaktadır.

(a) Saat kadranları üzerinde yuvarlak açıklıklar vardır. [W-GI37A2A3006-999]

(b) Benim yaşım 27 saçlarımın ön tarafı sizinki gibi arkasında da 6 cmlik yuvarlak bir açıklık var. [W-WI44F1D-5089-556]

Tümce (a) incelendiğinde yuvarlak kurulumu öntüre uygun ve kusursuz iken tümce (b) "biçimsel açıdan yuvarlağa benzeme" koşulu ile kabul edilebilir bir kurulum sağlanmaktadır. Bu açıdan etkin alan kurulumunda ikinci değişken olarak "öntür olarak yuvarlaklık” ele alınmıştır.

Çalışmada belirlenen son değişken ise $\dot{\mathrm{I}} / \mathrm{S}$ etkileşimidir. Tanık tümceler incelendiğinde yuvarlak sıfatının, öbek yapı oluşturduğu ad ile her zaman tam eşleşme kurma eğiliminde olmadığı gözlemlenmektedir. Bazı senaryolarda öngörülebilir eşleşme, bazılarında ise öngörülemeyen eşleşmelere rastlanmaktadır:

(a) İstanbul'da nelere inanılmadı ki (ve ola ki halen inanılıyor)? Dünyayı düşünelim, ilkin üzerinde yaşadığımız bu yuvarlak gezegeni... [WFI37C0A-1705-1445]

(b) Onu, hayal ettiği o dünyasında yuvarlak gözlüklerinin ardından seyrettik buğulu siluetlerde... [W-HH13C2A-3335-809]

(c) Top gibi yuvarlak bir kafa, geniş delikleri olan yine yuvarlak bir burun, genişçe bir çene, çatık, simsiyah, burun üstünde boşluk bırakmayı aklından geçirmemiş kaşlar, koca bir adamın avuçlayamayacağı kadar geniş omuzlar ve nasırlı, demir gibi eller. [WSA16B2A-0618-508]

Yukarıda sözü edilen gözlemler kapsamında yuvarlak sıfatının etkin alan kurulumlarını ortaya koymayı amaçlayan bu araştırma, anılan üç farklı dinamik üzerinden gerçekleştirilmiştir. 


\subsection{Yuvarlak Sifatının Etkin Alan Kurulumları}

\subsubsection{Küresel /Dairesel/Çembersel Açıdan Yuvarlaklık}

Sıfatın etkin alan kurulumlarındaki ilk dinamik etkileşimde bulunduğu adı küresel, dairesel ya da çembersel açıdan etkinleștirmesi üzerinedir. Daha sağlıklı bir analiz için küre, daire ve çember sözcüklerinin sözlük görünümlerine gereksinim duyulmaktadır. TDK Türkçe Sözlük’te (2011) yer alan tanımlar aşağıdaki gibidir:
Küre $\quad$ isim, matematik
Bütün noktaları merkezden aynı uzaklıkta
Daire isim, matematik bulunan bir yüzeyle sinırlı cisim.
Çember isim, matematik
Bir çemberin içinde kalan düzlem parçası.
Merkez denilen sabit bir noktadan aynı uzaklık ve düzlemdeki noktalar kümesinin oluşturduğu kapalı eğri.

Sözlük görünümleri incelendiğinde küre formunun üç boyutlu bir uzanımla kodlanırken daire formunun "çizgisellik+düzleme sahip olma", çember formunun ise "çizgisellik+düzleme sahip olmama" uzanımlarına sahip olduğu görülmektedir. Tanık tümcelerde yuvarlak sıfatı her üç içeriği de kodlama potansiyeline sahiptir. Söz konusu kodlama görünümleri Şekil 3'teki gibi somutlaştırılabilir.

Şekil 3. Yuvarlak sıfatının düzanlamsal uzanımları

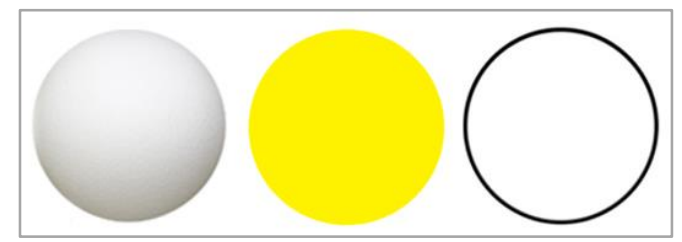

Yuvarlak sıfatının küresel uzanımla etkinleştirdiği kurulumlara aşağıdaki örnekler verilebilir.

(1) Böyle zamanlarda küçük, yuvarlak bașını omuzlarına gömer, gösterişsiz vücudu iyice küçülür, "aman rica ederim"leri, "estağfırullah"lar ağzının içinde geveler, bir an önce oradan çıkmak için kapıya doğru yavaşça ilerler, bir punduna getirip kaçardı. [WQA16B3A-1131-1676]

(2) Arkada karları parlayan yüksek bir dağ ve yuvarlak bir ay. [WRA14B1A-1582-1468] 
Tümce 1 ve tümce 2 kapsamında "yuvarlak baş" ile "yuvarlak ay" öbeklerinin küresel bir uzanıma sahip olduğu ve sıfatın adı üç boyutlu olarak etkinleştirdiğini söylemek mümkündür. Bu bağlamda eşdizimsel adın anlamsal içeriği etkin alan kurulumunda bir değişken olarak değerlendirilmekle birlikte her koşulda bu değişkenin işlemediği de elde edilen bulgular arasındadır:

(3) Ayvaları soyun, havuçla aynı irilikte doğrayın, tenceredeki et ve sebze karışımıyla birlikte ısıya dayanıklı yuvarlak bir cam tencereye alın. [W-SI41C1A-1455-1543]

Tümce 3 incelendiğinde tencere ögesinin de tıpkı baş ve ay gibi üç boyutlu bir anlam içeriğine sahip olmasına rağmen İ/S eşleşmesi tam olarak sağlanamadığı için (bkz. Bölüm 3.2.3.) küresel bir uzanıma sahip olan etkin alan kurulumu da sağlanamamaktadır.

Sıfatın dairesel kurulumları incelendiğinde küresel uzanımlarda olduğu gibi üç boyutlu olma niteliğinden öte çizgisel bir yuvarlaklık ve bu yuvarlaklığı dolduran bir düzlem uzanımları ön plana çıkmaktadır:

(4) Yuvarlak camlı gözlüklerini çıkartan Bahar, ellerini saçlarının arasında gezdirerek konuşmaya başladı. [W-RA16B3A-0649-165]

(5) $\mathrm{Bu}$ arada bir de yeni bir alışkanlık edinmiştim: Her tıraştan sonra, yuvarlak aynanın görüntüleri büyüten yüzüne bakıp ağzımı, burnumu, kulaklarımı, gözlerimi büyük bir merakla izliyordum. [W-MA16B1A0213-1212]

Tanık tümcelerin bir kısmında çembersel uzanımların kodlandığı ve uzanımların iki boyutluluğa daha yakın olma eğiliminde olduğu söylenebilir. Bu bağlamda söz konusu uzanımlar "Merkez denilen sabit bir noktadan aynı uzaklık ve düzlemdeki noktalar kümesinin oluşturduğu kapalı eğri." tanımıyla eşleşmektedir. Uzanımların dairesel uzanımlardan temel farkı, tanımda söz edilen "kapalı eğri”nin içerisinde bir düzlemin yer almamasıdır:

(6) Büyüteç kullanırken çıkarması gerektiğinden ince, yuvarlak, metal çerçeveli gözlügünü diğer elinde tutuyor. [W-RA16B2A-0629-490]

\subsection{2 Öntür Olarak Yuvarlaklık}

Öntür kavramı belirli bir ulamı en iyi temsil eden öge olarak değerlendirildiğinde yuvarlak sıfatının öntürsel görünümü "küre biçiminde olma ya da yarıçapının birbirine olan uzaklığı eşit olan dairesel ya da çembersel görünüm” koşulu olarak ele alınabilir. Tanık tümceler incelendiğinde senaryoların bir kısmında adların yuvarlak sıfatının öntürü kapsamında etkinleştiği gözlemlenmektedir: 
(7) Fakat radyonun içinden o sesler nasıl geliyor? Radyonun elektrik prizine takılan bir fişi var, oraya takılıp, kocaman yuvarlak düğmesi sağa çevrilip çıt edince, üstünde bir sürü yazılar olan mika bölümde sarı bir 1şı yanıyor ve başlıyor konuşmaya. [W-NI09C3A-0034-779]

(8) Ayvaları soyun, havuçla aynı irilikte doğrayın, tenceredeki et ve sebze karışımıyla birlikte 1sıya dayanıklı yuvarlak bir cam tencereye alın. [W-SI41C1A-1455-1543]

Tümceler incelendiğinde "yuvarlak düğme” ve "yuvarlak tencere" kurulumlarında öntürsel bir yuvarlaklık olasılığının yüksek olduğu söylenebilir. $\mathrm{Bu}$ açıdan anlamsal içerik senaryolaştırıldığında en merkezdeki noktanın kenarlara eşit yarıçaplarla dağıldığını söylemek mümkündür ${ }^{4}$. Öte yandan bazı kurulumların ise öntürden farklı uzaklıklara sahip olduğu gözlemlenmektedir:

(9) Gövde yanlarında koyu şeritler bulunur ve bu şeritler üzerinde yeşilimsi beyaz yuvarlak lekeler vardır. [W-RB04A1A-1160-1659]

(10) Akşam hiçbir şey yemediğim için enfes yuvarlak ekmekleri bir çırpıda mideye indirdim. [W-PE09C3A-1423-1562]

(11) Peynirlerin üzerine 2-3 dilim yuvarlak domates yerleştirip, kenarlarını 2 parmak genişliğinde ortaya doğru katlayalım. [W-RI22C4A-0804408]

Tümce 9 -11 incelendiğinde “yuvarlak leke”, “yuvarlak ekmek” ve "yuvarlak domates" öbekleri oluşan senaryoya bağlı olarak farklı uzanımlara sahip olabilmekte ve senaryo kurgusunda mükemmel bir yuvarlaklık koşulu aranmamaktadır. Şekil 4'te "yuvarlak leke” örneği üzerinden yuvarlak sıfatının öntür dış1 görünümü yer almaktadır:

Şekil 4. Yuvarlak sıfatının öntür dışı görünümü: “yuvarlak leke”

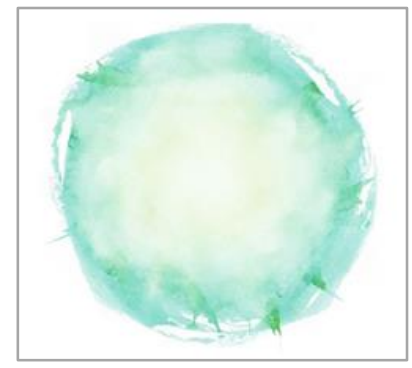

\footnotetext{
4 Öntüre uygunluğun "tam olarak" tespit edilebilmesi için göndergesel bilginin zorunlu bir koşul olması ve sadece yerleşik dünya bilgisinin yeterli olmaması durumu da göz önünde tutulmalıdır.
} 


\subsubsection{Imleyen-Sınır Eşleșmesi}

Tanık tümcelerdeki etkin alan kurulumları imleyen ve sınır açısından incelendiğinde, bazı kurulumlarda tam eşleşme sağlanırken bazılarında öngörülebilir bir parçada eşleşme ya da öngörülemez bir parçada eşleşmeler sağlanabilmektedir.

\subsubsection{Imleyen ve Sinırın Tamamen Eşleştiği Etkin Alanlar}

İncelenen bağımlı dizin görünümlerinde yuvarlak sıfatının, nitelediği adın tamamıyla etkileşime girdiği kurulumlara rastlanmaktadır. Bu kurulumların profillerinde İ ve S'nin tamamen birbiriyle eşleşebildiği gözlemlenmektedir. İ-S tam eşleşmelerinin gösteriminde İ ve S tamamen üst üste olduğu için İ'yi görmek teorik olarak mümkün değildir:

Şekil 5. İ ve S’nin tam eşleşme kurulumu

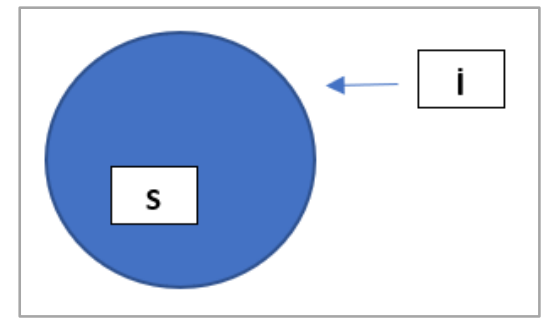

Söz konusu kurulumlarda kabul edilebilirlik koşulu olarak eşdizimsel ögenin biçimsel formunun tamamen yuvarlaklığa sahip olmasından söz edilebilir. Bu kurulumlar ayrıca öntür olarak yuvarlaklığa sahip olup olmama ve küresel/dairesel/çembersel yuvarlaklık gibi diğer değişkenler çerçevesinde farklılaşma eğilimindedir:

(12) Evlerin açık yaz pencerelerinde yanıp sönen parlaklıklarıyla gördüğü televizyonlardan ajans haberleri okunacak; iki kişilik sofralar kurulacak, bazen kan rengi, bazen altın suyu şaraplar uzun fakat yuvarlak ağızlı bardaklara konulacak ve onu hatırlayacaktı. [WFA16B1A-0390-729]

(13) İstanbul'da nelere inanılmadı ki (ve ola ki halen inanılıyor)? Dünyayı düşünelim, ilkin üzerinde yaşadığımız bu yuvarlak gezegeni... [WFI37C0A-1705-1445]

Tümceler incelendiğinde "yuvarlak ağız" ve "yuvarlak gezegen” öbeklerinde İS eşleşmesinin tamamen kurulabildiği gözlemlenmektedir. Öte yandan bardak için "yuvarlak ağız" öbeğinde öntüre daha uygun ve çembersel bir uzanım 
kodlanırken "yuvarlak gezegen” öbeğinde öntür dıșı ve küresel bir uzanımla karşılaşılmaktadır. $\mathrm{Bu}$ açıdan söz konusu üç temel değişkenin farklı kombinasyonlarının farklı etkin alan kurulumları oluşturduğundan söz etmek mümkündür (bkz. Sonuç ve Tartışma).

\subsubsection{Imleyenin Sınırın Bir Parçasıyla Eşleştiği Etkin Alanlar}

İmleyen ve sınırın parçasal eşleşmesine ilişkin iki farklı senaryodan söz edilebilir. Bunlardan ilki imleyenin sınırın öngörülebilir bir parçasıyla eşleştiği etkin alanlardır. Söz konusu kurulumlarda dil kullanıcısı imleyenin sınırı nereye kadar etkinleştirebildiğini bilişsel açıdan kurgulayabilmektedir.

Şekil 6. İ ve S’nin öngörülebilir eşleşme kurulumu

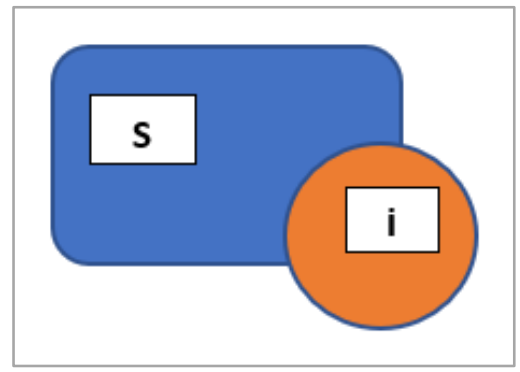

İ-S'nin öngörülebilir eşleşme kurulumlarında dil kullanıcısı eşleşmenin nerede başladığını ve nerede bittiğini doğrudan algılayabilir. Diğer bir deyişle dil kullanıcısının doğal artalan bilgisi, bilişsel ve net bir çerçeve oluşturmaya yardımcı olmaktadır:

(14) Yuvarlak bir masanın çevresinde biz beş kişi, beş kişi de onlardan, sıralandik. [W-SA16B1A-0768-157]

(15) Metal çerçeveli, yuvarlak "entel" gözlükler kullanıyor, dirseklerine kadar gümüş bilezikler takıyordu. [W-NI22C2A-0169-1455]

Tümceler incelendiğinde "yuvarlak masa" ve "yuvarlak gözlük" öbeklerinde masanın ya da gözlügün tamamının değil belirli ve tahmin edilebilir bir alanın etkinleştiği bilgisinin, doğrudan dil kullanıcısının artalanında yer alan bir bilgi olması sebebiyle söz konusu kurulumlar tahmin edilebilir bir etkinleştirme alanına sahiptir.

İmleyenin sınırın bir parçasıyla eşleştiği etkin alanlara ilişkin ikinci senaryo ise imleyenin sınırın öngörülemez bir parçasıyla eşleştiği görünümlerdir. Söz konusu etkinleştirmelerde birden fazla potansiyel İ/S eşleşmesinden söz etmek mümkündür: 
Şekil 7. İ ve S'nin öngörülemez eşleşme kurulumu

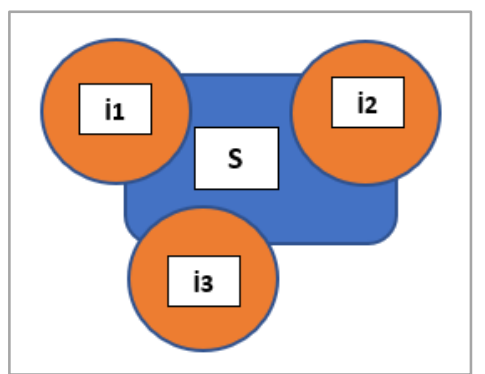

Tanık tümceler incelendiğinde özellikle VÜCUT BÖLÜMÜ anlamsal ulamı altında değerlendirilebilecek eşdizimsel adların öngörülemez eşleşme kurulumuna sahip olduğu gözlemlenmektedir:

(16) Onun da iri gözleri, geniş alnı, yuvarlak çenesi, düşük omuzları var. [W-NA16B1A-1736-1437]

(17) Yuvarlak göğüslere dokunup dokunmamakta tereddüt etti ama dokundu. [W-VA16B4A-1030-319]

(18) Çarpıcı yaratı̆̆ın uzun bacaklarının ve sıkı yuvarlak kalçalarının hareketlerini izleyerek ilerliyordum ki, birden genç kızın ani dönüşüyle onunla burun buruna geliverdim. [W-EA16B2A-1740-1432]

"Yuvarlak çene", "yuvarlak göğüs", "yuvarlak kalça" öbekleri incelendiğinde sıfatın etkinleştirdiği alanları bilişsel olarak tam olarak belirlemenin mümkün olmadığ1 söylenebilir. Bu kapsamda söz konusu içeriklerde İS eşleşmesi öngörülemeyen bir kurulumla karşımıza çıkmaktadır.

\subsubsection{Diğer Gözlemler}

Çalışmada, yukarıda sözü edilen üç dinamik kapsamında doğrudan incelenmeyen fakat etkin alan kurulumlarına önemli perspektifler sunabilecek olan dört farklı koşulla karşılaşılmıştır. Bunlardan ilki aynı öbek yapı/anlamsal kurulum içerisinde iki farklı biçimlendirme uzanımının olmasıdır:

(19) Yuvarlak bir dairenin etrafina sıralanmış tuş takımıyla diğer telefonlardan oldukça farklı olan CL100, odanızın dekorasyonuna uyumlu olması açısından "Golden Braun" ve "Shining Indigo" olmak üzere iki farklı renkte üretildi.

(20) Yuvarlak demir elipslerden işlenmiş kepenkler kalkarken gürültüler çıkardı, işgaliyesi ödenmemiş kumlar, sepetler, kasalar, sokakların iki yanında, az önce arapsabunuyla yıkanan yerleri bezedi. 
Tanık tümceler incelendiğinde "yuvarlak daire" ve "yuvarlak elips" ögelerinde yuvarlak sıfatının daire ve elips gibi ikinci bir fiziksel sınırlandırma yapan içeriklerle kullanıldığı gözlemlenmektedir. "Yuvarlak daire" kurulumunda temelde belirli bir düzleme sahip olan daire yapısı çembersel konuma gelmektedir. "Yuvarlak elips" kurulumunda ise elips içeriği geometrik bir kavram olmaktan uzaklaşarak nesneleşme eğiliminde olmakta ve sıfat bu nesnenin fiziksel sınırlarını etkinleştirmektedir.

Araştırmada karşılaşılan ikinci gözlem olarak ise yuvarlak sıfatının şekil, biçim, form gibi doğrudan fiziksel gönderime sahip eşdizimsel ögelerle kurulum sergileyebilmesidir.

(21) Besin öğesi miktarlarını yuvarlak şekillerle belirten etiket örneği ise son sırayı almıştır.

(22) Herkes çamaşırlarını sırf bu iş için imal edilmiş olan yuvarlak biçimli kendinden mandallı plastiklere asıyor.

Tümce 21 ve 22 incelendiğinde öbek yapının anlam içeriğinde kurulumun tamamen sağlanamadığı, söz konusu etkinleştirmenin bağlam içerisindeki başka bir varlığa/nesneye gönderimde bulunduğu gözlemlenmektedir. Bu kapsamda "yuvarlak şekil" öbeğinin etiketleri, "yuvarlak biçim” öbeğinin ise plastikleri etkinleştirdiği söylenebilir.

Üçüncü gözlem ise sıfatın etkinleştirdiği alanda herhangi bir varlık olmaması koşuluyla bir kurulum sağlanabilmesi üzerinedir:

(23) Külâhın altında, çeşitli boyda, yuvarlak boşlukları dolduran çinilerden, belki sırlı çanaklar da olabilir, bugün hiçbir iz kalmamıştır. [W-DG03A4A-2997-1016]

(24) Sonlarındaki küçük yuvarlak deliklerinden bu dev iğneye geçirilmiş küçük çengellilerden birini çıkardı. [W-SA16B2A-1070-1699]

Tümce 23 ve 24'te "yuvarlak boşluk" ve "yuvarlak delik” öbeklerinin bilişsel açıdan kurgulanabilmesi için yuvarlaklığın etkinleştirdiği bölgede herhangi bir oluşuma rastlanmaması gerekmektedir.

Dördüncü ve son gözlem ise aynı dizilimde yuvarlak sıfatı dışında bir ya da daha fazla sıfat kullanılması üzerinedir. Söz konusu dizilim kapsamında iki farklı koşulla karşılaşılmaktadır. İlk koşulda sıfatın nitelediği ad bulanıklığa yol açmadan izlenebilir konumdadır. Bu açıdan her niteleyici farklı ve özerk boyutlarda etkin alan kurulumu oluşturabilmekte ve yuvarlak sıfatı etkin alan kurulumu açısından farklı bir eğilim göstermemektedir. İkinci koşulda ise sıfat diziliminin oluşturduğu öbek yapı birden fazla sözdizimsel okumayı olanaklı kılmaktadır: 
(25) Onun, yüzüne göre çok iri, yuvarlak, nemli ve hayretle açılmış gözlerinden ve çocuk-kadın havasından çok hoşlanmıştı. [WOA16B4A-0119-1641]

(26) Köyün meydanında rastladığı kıvırcık saçlı, küçük, yuvarlak, numaralı gözlüklü, kıvırcık kirpikli, o çok güzel gülümseyen adamı düşündü Banu. [W-EA16B4A-0688-462]

(27) Büyüteç kullanırken çıkarması gerektiğinden ince, yuvarlak, metal çerçeveli gözlüğünü diğer elinde tutuyor. [W-RA16B2A-0629-490]

Tümce 25 incelendiğinde yuvarlak sıfatı çok iri, nemli, hayretle açılmış sıfatlarıyla aynı dizgede kullanılmakta ve doğrudan ortak bir adı nitelemektedir. Tümce 26 ve Tümce 27 incelendiğinde ise sıfatın, içerisinde bulunduğu dizilimde birden fazla ad öbeği ile anlamsal açıdan kabuledilebilirlik koşullarını sağlaması nedeniyle, iki farklı sözdizimsel okuma olanaklı hale gelmektedir. Biçim-sözdizimsel alanyazında parantezleme paradoksu (bracketing paradox) olarak değerlendirilen bu görünümü Tümce 27 kapsamında aşağıdaki gibi somutlaştırmak mümkündür:

- [[sö ince] [[sö yuvarlak] [[sö metal çerçeveli] [Aö gözlük]]]]

- [[[[sö ince] [[sö yuvarlak] [[sö metal] [Aö çerçeve]]]] sö li] [Aö gözlük]]

Bu kapsamda ilk okumada ince, yuvarlak ve metal çerçeveli sıfatları doğrudan gözlük adı ile; ikinci okumada ise ince, yuvarlak ve metal sıfatları çerçeve adı ile öbek yapı oluşturmakta ve sonrasında gözlük adına eklenti olarak katılmaktadır. Etkin alan kurulumları açısından ilk okumada yuvarlak sıfatı gözlük adını etkinleştirirken ikinci okumada araştırma konusu sıfat çerçeve adını etkinleştirmektedir.

\section{Tartışma ve Sonuç}

$\mathrm{Bu}$ çalışmada biçim sıfatı olan ve nesnelere doğrudan fiziksel bir sınırlama getiren "yuvarlak" sıfatının etkin alan kurulumları konu edilmiştir. Çalışmada yuvarlak sıfatının derlem temelli görünümleri TUD v3 Yazılı Metin Sorgusu seçeneği aracılığıyla ortaya konmuştur. Bu kapsamda sıfatın bağlam içi anahtar sözcük görünümlerine ulaşılmış ve datalar araştırmacı tarafından işlenmiş/sınıflandırılmıştır. Yuvarlak sıfatının etkin alan kurulumlarında üç temel değişkenden söz etmek mümkündür: Bunlardan ilki söz konusu sıfatın etkileşimde bulunduğu adı küresel, dairesel ya da çembersel açılardan etkinleştirmesi üzerinedir. Tanık tümceler incelendiğinde eşdizimsel adın uzanımlarına bağlı olarak "tüm noktaları merkezden aynı uzaklıkta bulunma ve üç boyutlu bir cisim olma" niteliğinde sahip olmak koşuluyla küresel bir etkinleştirmeden söz etmek mümkündür: "yuvarlak baş" ve "yuvarlak ay" öbekleri buna örnek olarak verilebilir. Dairesel etkinleştirmelerde ise "yuvarlak cam" ve "yuvarlak ayna" öbeklerinde olduğu gibi “çizgisel bir yuvarlaklık ve bu 
yuvarlaklığı dolduran bir düzlem" uzanımı ön plana çıkmaktadır. Sıfatın çembersel etkileşimleri ise "kapalı bir eğrinin içerisinde bir düzlemin yer almaması" koşuluyla karşımıza çıkmaktadır. Söz konusu çembersel etkileşimleri "yuvarlak çerçeve" öbeği örneklemektedir.

Yuvarlak sıfatının etkinleştirme kurulumlarında "öntür olarak yuvarlaklık" ikinci değişken olarak karşımıza çıkmaktadır. Kurulumların bir kısmında yuvarlaklık "küre biçiminde olma ya da yarıçapının birbirine olan uzaklığı eşit olan dairesel ya da çembersel görünüm" koşulunu karşılarken bir kısmında kurulumların öntürden farklı uzaklıklara sahip olduğu gözlemlenmektedir. Bu kapsamda "yuvarlak düğme" ve "yuvarlak tencere" öbeklerinde öntürsel bir etkinleştirme söz konusu iken "yuvarlak leke”, “yuvarlak ekmek”, “yuvarlak domates" öbeklerinde öntürden uzaklaşan bir kurulumla karşılaşılmaktadır.

Çalışmada ortaya konan üçüncü dinamik ise $\dot{I} / S$ etkileşimleridir. Tanık tümcelerdeki etkin alan kurulumları imleyen ve sınır açısından incelendiğinde, bazı kurulumlarda tam eşleşme sağlanırken bazılarında öngörülebilir bir parçada eşleşme ya da öngörülemez bir parçada eşleşmeler sağlanabilmektedir: “yuvarlak ağız” ve "yuvarlak gezegen” kurulumlarında tam eşleşme sağlanırken "yuvarlak masa" ve "yuvarlak gözlük” kurulumlarında öngörülebilir bir eşleşme sağlanmakta, "yuvarlak çene”, "yuvarlak göğüs”, “yuvarlak kalça” öbeklerinde ise bilişsel senaryonun öngörülebilir biçimde kurgulanamadığ1 gözlemlenmektedir.

Çalışmada elde edilen önemli sonuçlardan biri de farklı etkinleştirme dinamiklerinin farklı birliktelikleri sunması üzerinedir. Örneğin küresel olarak yuvarlaklık görünümlerinde büyük oranda İ/S eşleşmesi tam olarak sağlanırken çembersel olarak yuvarlaklıkta birbirinden farklı senaryolarla karşılaşılmaktadır. Tablo 3'te etkin alan kurulumuna ilişkin dinamiklerin simgesel görünümleri, Tablo 4'te ise söz konusu dinamiklerin farklı kombinasyonları yer almaktadır.

Tablo 3. Yuvarlak sıfatı etkin alan kurulumuna ilişkin dinamikler

\begin{tabular}{ccl}
\hline Dinamik & Ulam No & \multicolumn{1}{c}{ Dinamik Alt Ulam } \\
\hline $\mathbf{1}$ & $\mathbf{1 a}$ & küresel açıdan yuvarlaklık \\
& $\mathbf{1 b}$ & $\begin{array}{l}\text { dairesel açıdan yuvarlaklık } \\
\text { çembersel açıdan yuvarlaklık }\end{array}$ \\
\hline $\mathbf{1 c}$ & $\mathbf{2 a}$ & öntür olarak yuvarlaklık (+) \\
$\mathbf{2}$ & $\mathbf{2 b}$ & öntür olarak yuvarlaklık (-) \\
\hline $\mathbf{3}$ & $\mathbf{3 a}$ & imleyen ve sınırın tamamen eşleştiği \\
& $\mathbf{3 b}$ & $\begin{array}{l}\text { yuvarlaklık } \\
\text { imleyen ve sınırın öngörülebilir biçimde } \\
\text { eşleştiği yuvarlaklık } \\
\end{array}$ \\
& $\mathbf{3 c}$ & $\begin{array}{l}\text { imleyen ve sınırın öngörülemez biçimde } \\
\text { eşleştiği yuvarlaklık }\end{array}$ \\
\hline
\end{tabular}


Tablo 4. Yuvarlak sıfatı etkin alan kombinasyonları

\begin{tabular}{ccccccccc}
\hline & $\mathbf{1 a}$ & $\mathbf{1 b}$ & $\mathbf{1 c}$ & $\mathbf{2 a}$ & $\mathbf{2 b}$ & $\mathbf{3 a}$ & $\mathbf{3 b}$ & $\mathbf{3 c}$ \\
\hline ay & + & - & - & - & + & + & - & - \\
ayna & - & + & - & + & - & + & - & - \\
baş & + & - & - & - & + & + & - & - \\
cam & - & + & - & + & - & + & - & - \\
çene & + & - & - & - & + & - & - & + \\
çerçeve & - & - & + & + & - & + & - & - \\
domates & + & - & - & - & + & + & - & - \\
düğme & - & + & - & + & - & + & - & - \\
ekmek & + & - & - & - & + & + & - & - \\
gezegen & + & - & - & - & + & + & - & - \\
göğ̈̈s & + & - & - & - & + & - & - & + \\
gözlük & - & + & - & + & - & - & + & - \\
kalça & + & - & - & - & + & - & - & + \\
leke & - & + & - & - & + & - & - & + \\
masa & - & + & - & + & - & - & + & - \\
tencere & - & + & - & + & - & - & + & - \\
\hline
\end{tabular}

Elde edilen sonuçlar kapsamında araştırma konusu sıfatın etkin alan kurulumlarına ilişkin aşağıdaki çıkarımları yapmak mümkündür:

- Yuvarlak sıfatı kurulumsal açıdan, aynı dizgeye girdiği adı "küresel", “dairesel” ya da "çembersel” olmak üzere üç farklı eşleşme dinamiği ile etkinleştirebilmektedir.

- Sıfatın etkinleştirme görünümlerinde öbek yapıların bir kısmı öntür olarak "yuvarlaklık" kapsamında uzanıma sahipken bir kısmı öntürden uzaklaşmaktadır.

- Sıfatın etkin alan kurulumları imleyen ve sınır açısından incelendiğinde, bazı kurulumlarda tam eşleşme sağlanırken bazılarında öngörülebilir bir parçada eşleşme ya da öngörülemez bir parçada eşleşmeler sağlanabilmektedir.

Söz konusu üç dinamik kapsamında doğrudan incelenmeyen fakat etkin alan kurulumlarına önemli perspektifler sunabilecek olan dört farklı koşulla karşılaşılmıştır. Bunlardan ilki aynı öbek yapı/anlamsal kurulum içerisinde iki farklı biçimlendirme uzanımının olmasıdır: "yuvarlak daire" ve "yuvarlak elips" öbekleri söz konusu kuruluma örnek oluşturmaktadır. Araştırmada karşılaşılan ikinci koşul ise olarak yuvarlak sıfatının şekil, biçim, form gibi doğrudan fiziksel gönderime sahip eşdizimsel ögelerle kurulum sergileyebilmesidir. $\mathrm{Bu}$ kurulumların tam olarak anlamsal bir içeriğe sahip olmadığı, tam kurulum sağlanabilmesi için bağlam içerisindeki başka bir ögeye gönderimde bulunması gerektiği söylenebilir. Üçüncü gözlem sıfatın etkinleştirdiği alanda herhangi bir 
varlık olmaması koşuluyla bir kurulum sağlanabilmesi üzerinedir: "yuvarlak boşluk" ve "yuvarlak delik" öbekleri bu kapsamda değerlendirilebilir. Son gözlem ise yuvarlak sıfatının başka sıfatlarla aynı dizilimde olmasına ilişkindir. $\mathrm{Bu}$ kapsamda ya her sıfat, anlamsal bulanıklığa yol açmadan doğrudan aynı adı nitelemekte ya da birden fazla ad öbeği ile anlamsal açıdan kabuledilebilirlik koşullarını sağlaması nedeniyle iki farklı sözdizimsel okumaya izin vermektedir. $\mathrm{Bu}$ koşulda dil kullanıcısının yargısının önemli bir karar mekanizması olduğu düşünülmektedir.

Öte yandan, etkin alan kurulumları bilişsel anlambilim alanyazınında kuramsal olarak yer bulmuş ve fakat doğal dilsel veriler üzerinden kapsamlı olarak çalışılmamış bir alan olarak karşımıza çıkmaktadır. Kuramsal açıdan Langacker (1999) etkin alanları eylem-tamlayıcı açısından ele almakta ve örnek dilsel kesitlerle savını güçlendirmektedir. Ayrıca Cruse (2000) dilde etkin alan kurulumlarını blue ve red sıfatları üzerinden sınırlı bir örnekler kümesiyle açıklamaktadır. Bu açıdan yuvarlak sıfatının etkin alan kurulumlarıyla ilgili diller arası karşılaştırma yapmaya elverişli bir araştırmaya rastlanmamıştır. Alanyazında doğrudan yuvarlak sıfatı ile ilgili olmasa da Türkçe sıfatlarda etkin alan kurulumları kapsamında Gündoğdu'nun (2019) kırmızı sıfatının adı etkinleştirme eğilimlerini doğal dilsel veriler aracılığıyla incelediği bir çalışmaya rastlanmıştır. Bir renk sıfatı olan kırmızı yalnızca İ/S etkileşimi bakımından ele alınabilirken biçim sıfatı olan yuvarlak etkin alan kurulumu açısından üç farklı değişken çerçevesinde değerlendirilebilmektedir. Bu açıdan, sıfat kategorilerinin etkin alan kurulumunda önemli bir değişken olduğu gözlemlenmektedir: Sifat kategorisi değiştikçe farklı etkinleştirme kurulumları ile karşılaşılacağı öngörülmektedir. Sonuç olarak anlamlama ve kavramlaştırmanın "sözlüksel" değil "ansiklopedik" olduğu göz önüne alındığında, bir sıfatın anlambilimsel düzlemlerini ortaya koyma açısından etkin alan kurulumlarının önemli bir araştırma alanı olduğu düşünülmektedir.

\section{Kaynakça}

Aksan, Y., Aksan, M., Koltuksuz, A., Sezer, T., Mersinli, Ü., Demirhan, U. U., Yılmazer, H., Atasoy, G., Öz, S., Yıldız, İ. ve Kurtoğlu, Ö. (2012). Construction of the Turkish National Corpus (TNC). Calzolari, N., Choukri, K., Declerck, T., Doğan, M. U., Maegaard, B., Miriani, J., Odijk, J. ve Piperidis, S. (Yay. haz.) içinde, Proceedings of the Eight International Conference on Language Resources and Evaluation (LREC 2012). İstanbul, Türkiye. http://www.lrec-conf.org/proceedings/lrec2012/papers.html.

Cruse, A. (2000). Meaning in language: An introduction to semantics and pragmatics. Oxford: Oxford University Press.

Dixon, R. M. W. (2005). A semantic approach to English grammar. Oxford: Oxford University Press.

Erkuş, A. (2009). Davranış bilimleri için bilimsel araştırma süreci. Ankara: Seçkin Yayıncilık. 
Evans, V. (2007). A glossary of cognitive linguistics. Edinburgh: Edinburgh University Press.

Evans, V. (2012). Cognitive linguistics. Wiley Interdisciplinary Reviews: Cognitive Science. 3 (2), 129-141.

Frawley, W. (1992). Linguistic semantics. London: Routledge.

Glesne, C. (2013). Nitel araştırmaya giriş. (Çev. A. Ersoy ve P. Yalçınoğlu) Ankara: Anı Yayınc1lik.

Gündoğdu, A. E. (2019) Türkçede etkin alanların bilişsel anlambilim açısından incelenmesi: "kırmızı" sıfatı örneği. Mersin Üniversitesi Dil ve Edebiyat Dergisi, MEUDED. 16 (2), 111-133.

Langacker, L. (1999). Grammar and conceptualization. Berlin / New York: Mouton de Gruyter.

Langacker, L. (2004). Metonymy in grammar. Journal of Foreign Languages. 6, 2-24.

Murphy, M. L. (2010). Lexical meaning. Cambridge: Cambridge University Press.

Tavşancıl, E. ve Aslan, A. E. (2001). İçerik analizi ve uygulama örnekleri. İstanbul: Epsilon Yayınevi.

TDK (2011). Türk Dil Kurumu Türkçe sözlük. Ankara: TDK Yayınları. 